\title{
An Extension of Mohring's Model for Land Rent Distribution ${ }^{1}$
}

\author{
ROLAND ANDERSSON \\ Department of Economics, University of Stockholm, Stockholm, Sweden \\ AND \\ AVElino Samartin \\ Department of Structural Analysis, University of Santander, Santander, Spain
}

\begin{abstract}
In an early paper Herbert Mohring ( $J$. Pol. Econ., 49 (1961)) presented a model for land rent distribution yielding the well-known result that the price of land must fall with the distance from the city center to offset transportation costs. Our paper is an extension of Mohring's model in which we relax some of his drastic simplifying assumptions. This extended model has been incorporated in a method for economic evaluation of city master plans which has been applied to a Swedish city. In this method the interdependence among housing, heating, and transportation, the durability of urban structures, and the uncertainty of future demand are explicitly considered within a cost-benefit approach. Some empirical results from this pilot study concerning land rent distributions are also presented here.
\end{abstract}

\section{INTRODUCTION}

Land rent has been a well established concept in economic theory since the times of Ricardo and von Thünen. Land rent is defined as the economic surplus per unit of land area per unit of time. This means that land rent depends on the location of the site. Land value at a particular site and time is the present value of future land rents.

Recently, the Alonso-Mills-Muth model has been the standard in urban economics $[1,13,16]$. An important direction in research during recent years is based on the recognition that urban capital is durable but not malleable $[19,17,9,20]$. Also in the "new urban economics" welfare economics has been applied to urban problems $[14,18,11,10]$.

\footnotetext{
${ }^{1}$ Fil dr Mats Bohman and fil kand Hans Wijkander of the Department of Economics at the University of Stockholm have presented valuable comments to an earlier version of this paper. Discussions with fil dr Magnus Holm, Sinova AB, have been of great value for this paper. We also thank Professor Edwin S. Mills for his suggested editorial improvements of our paper. The Swedish Council for Building Research has financed the research.
} 
In this paper we return to a pioneering article on land rent distribution by Herbert Mohring [15]. In this model the price of land must fall with the distance from the city center to offset transportation costs, which increase with distance, for there to be equilibrium. Although Mohring's model is based on drastic simplifications it has attractive characteristics.

The purpose of this paper is to present an extension of Mohring's model of land rent distribution. This extended model has been applied in connection with a method for the economic evaluation of city master plans where the interdependence among housing, heating, and transportation, the durability of urban structures, and the uncertainty of future demand are explicitly considered within a cost-benefit approach [6].

This paper starts with a survey of Mohring's model. After that, the main assumptions introduced to extend Mohring's model are discussed. The extended model for the determination of land rent distribution and an application of the extended model to an economic evaluation of city master plans are then presented. Finally, some suggestions for continued research and some conclusions are given.

\section{A SURVEY OF MOHRING'S MODEL}

Mohring's is an equilibrium model based on the following assumptions:

1. Household size is the same throughout the city. Households have identical preferences and incomes.

2. Commuting costs are proportional to distance from the residence to the Central Business District (CBD).

3. All workers commute to and from the $\mathrm{CBD}$, which is a point.

4. All residences are single-family houses located on lots of the same size.

Equilibrium in Mohring's model is a situation in which no household would be able to gain by moving to another location. This can be expressed as

$$
\mathrm{cc}_{n}+\mathrm{ar}_{n}=\mathrm{cc}_{m}+\mathrm{ar}_{m}
$$

where

$\mathrm{cc}_{n}$ and $\mathrm{cc}_{m}$ are the individual commuting costs from residential nodes $n$ and $m$, respectively, to the CBD per unit of time, and

$\operatorname{ar}_{n}$ and $\operatorname{ar}_{m}$ are rents for apartments at nodes $n$ and $m$, respectively.

Equation (1) means that "all families are content to stay where they are" [15, p. 237]. It can be simplified to

$$
\mathrm{cc}_{n}+\mathrm{ar}_{n}=\text { constant. }
$$




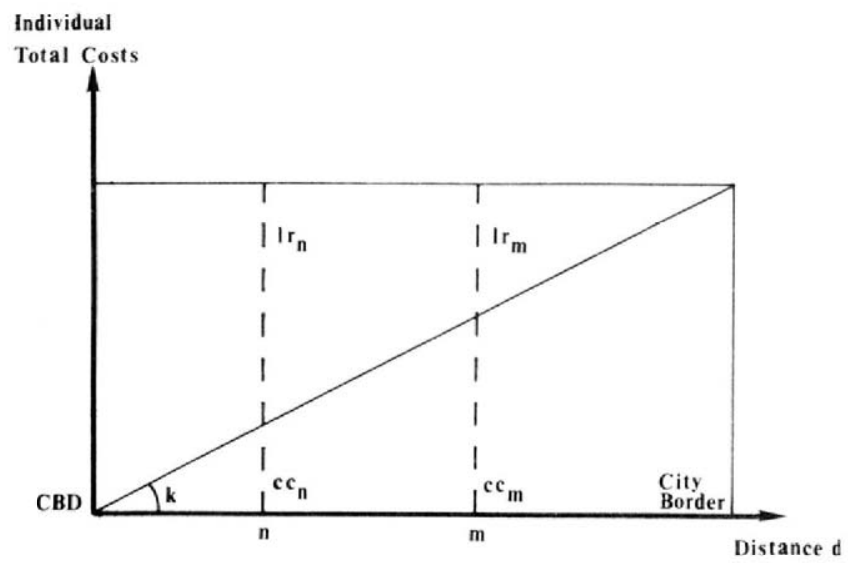

FIG. 1. Representation of Mohring's model.

Equation (1) means that an increase (or decrease) in individual commuting costs between the two nodes must be counterbalanced exactly by a decrease (or increase) in the residential rents.

Mohring's assumptions imply the following functions for transportation costs and house rents:

$$
\mathrm{cc}_{n}=k \cdot d
$$

and

$$
\mathrm{ar}_{n}=1 \mathrm{r}_{n}+\mathrm{bc}_{n}=1 \mathrm{r}_{n}+p_{0}
$$

where

$d$ is the distance between residence $n$ and the CBD,

$k$ is a constant proportion, $\mathrm{bc}_{n}=p_{0}$ is the structure rent.

Thus, (2) can be written

$$
k \cdot d+1 \mathrm{r}_{n}=\text { constant. }
$$

Equation (5) is illustrated by Fig. 1.

Commuting costs are nil in the CBD. This implies that the land rent there is the maximum value. At the city limits, commuting costs are greatest and the land rent is at a minimum value equal to the rent for land in agricultural use. Mohring assumed this value to be nil, permitting the value of the constant of (3) to be deduced. Then, using (5), the land rent distribution over the city can be determined. 
Here are some observations about the simplifying assumptions used in Mohring's model. First, there are differences in household size, preferences, and income in real cities. Second, commuting costs depend strongly not only on the distance but also on a number of other factors including the transportation layout, the mode of commuting selected, parking fees, and bus fares. Third, there are usually several work place centers in a city, and finally, as Mohring points out, population density is usually greater where land rent is greater. This means that multifamily residences are constructed and that the habitable space per household as well as the size of the lots decrease for each income class [3] when land rent increases.

\section{MAIN ASSUMPTIONS USED TO EXTEND MOHRING'S MODEL}

We will extend Mohring's model as follows:

1. There are several income classes in a city.

2. Commuting costs depend on the layout of the transportation system, the mode of commuting chosen, congestion, parking fees, and so on.

3. There may be several work place centers in the city. The number of commuting trips does not depend on the distance traveled (as in Mohring's model).

4. Residences may be in multifamily as well as single-family buildings and both the habitable space per household and the size of the lots may vary from one node to another.

Equation (2) is changed as follows:

$$
\mathrm{cc}_{n}+\mathrm{ar}_{n}=\mathrm{ic}^{*}
$$

where

$\mathrm{cc}_{n}$ now represents individual commuting costs from residential node $n$ to the selected work place center $p$ per unit of time,

$\operatorname{ar}_{n}$ is the dwelling rent at residential node $n$ and

ic* is a constant for a specific income class ic, though the constant is different for different income classes. ${ }^{1}$

The expression for $\mathrm{cc}_{n}$ of (3) is changed as follows:

$$
\mathrm{cc}_{n}=2 c_{\mathrm{bn}} \frac{\mathrm{NDAY}}{365}
$$

\footnotetext{
${ }^{1}$ This idea was introduced following discussions with Professor John Quigley of the Department of Economics at the University of California, Berkeley.
} 
where

$2 c_{\mathrm{bn}} \quad$ is the individual commuting costs (back and forth) per worker each day, ${ }^{2}$

NDAY is the number of working days per year.

The individual commuting costs per worker $c_{\text {bn }}$ depend not only on the node of residence but also on the working place center, route, and mode of transportation chosen by individuals living at node $n$. In the model for the economic evaluation of master city plans developed by Andersson and Samartin [4] the route and mode of transportation are determined by minimizing individual commuting costs. The work place center is determined using a gravity rule. An attraction factor is defined for each work place center proportional to the number of job opportunities at the center and for each residential node proportional to the number of inhabitants. The minimum commuting costs for all possible routes and modes of transportation between the residential node and the work place center provide a coefficient that is inversely proportional to the attraction factor. Details of the computational procedures are to be found in Andersson and Samartin [4].

The value of $\operatorname{ar}_{n}$ given in (4) will now be changed as follows:

$$
\mathrm{ar}_{n}=\alpha_{n}\left(\mathrm{bc}_{n}+\frac{1}{\alpha_{\mathrm{ln}}}\right)
$$

where

$\alpha_{n}$ is the habitable area demanded per individual,

$\alpha_{\ln }$ is the number of stories per residential building at node $n$,

$1 r_{n}$ is the land rent (per day per unit of land area) and

$\mathrm{bc}_{n}$ is the building costs per day per unit of habitable area. ${ }^{3}$

In addition to these altered assumptions, a new assumption about the demand for habitable space is introduced. The habitable area demanded per worker is assumed to depend on price and income, so that,

$$
\alpha_{n}=h\left(\mathrm{ic}_{n}\right)^{\theta_{1}} \cdot\left(\operatorname{ar}_{n}\right)^{\theta_{2}}
$$

\footnotetext{
${ }^{2}$ The expression for $c_{\mathrm{bn}}$ is given for each mode of commuting in Appendix $\mathrm{A}$ of Andersson and Samartin [4].

${ }^{3}$ The expression giving these building costs as a function of the number of stories is given in Appendix A.
} 
where

$h \quad$ is a constant,

ic $_{n} \quad$ is the income per day of a worker living at node $n$,

$\operatorname{ar}_{n} \quad$ is the daily rent for a unit area of habitable space at node $n$ and

$\theta_{1}$ and $\theta_{2}$ are elasticity coefficients for income and apartment rent, respectively.

\section{THE EXTENDED MODEL FOR DETERMINATION OF LAND RENT DISTRIBUTION}

The extended model presented in Section III can be used to obtain the land rent distribution over the area of the city in the following way. First, for each income class, the constant ic* of (6) has to be determined. It is assumed that all of the inhabitants of a given node belong to a single income class. How the various income classes are distributed among the nodes is part of the input data to the model. Applying (8) and (9) to (6) we obtain

$$
2 \cdot c_{\mathrm{bn}} \cdot \frac{\mathrm{NDAY}}{365}+\alpha_{n} \cdot \mathrm{bc}_{n}+\frac{\alpha_{n}}{\alpha_{\mathrm{ln}}} \cdot \mathrm{lr}_{n}=\mathrm{ic}^{*}
$$

or, equivalently,

$$
2 \cdot c_{\mathrm{bn}} \cdot \frac{\mathrm{NDAY}}{365} \cdot \frac{\alpha_{\ln }}{\alpha_{n}}+\alpha_{\ln } \cdot \mathrm{bc}_{n}+\operatorname{lr}_{n}=\frac{\alpha_{\ln }}{\alpha_{n}} \cdot \mathrm{ic}^{*} .
$$

It can be assumed that the expression $\left(\alpha_{\ln } / \alpha_{n}\right)$ ic* is approximately constant for a given income class. ${ }^{4}$ Because of this assumption, node $n_{0}$, the node at which the land rent is lowest, is also the node for which the following expression is greatest:

$$
L_{n}=2 \cdot c_{\mathrm{bn}} \cdot \frac{\mathrm{NDAY}}{365} \cdot \frac{\alpha_{\ln }}{\alpha_{n}}+\alpha_{\ln } \cdot \mathrm{bc}_{n}
$$

and

$$
L_{n}=\text { maximum for } n=n_{0} \text {. }
$$

${ }^{4}$ This assumption is introduced for the sake of simplicity in the computational procedure to make it straightforward to locate node $n_{0}$, the node at which the land rent is lowest. If this hypothesis does not hold, an iterative computational procedure must be used. For example, the land rent values can be successively corrected at each computational step, assuming that the $\left(\alpha_{\ln } / \alpha_{n}\right)$ ratio is already known. The iterations can be initiated with a constant ratio as an initial trial value. 


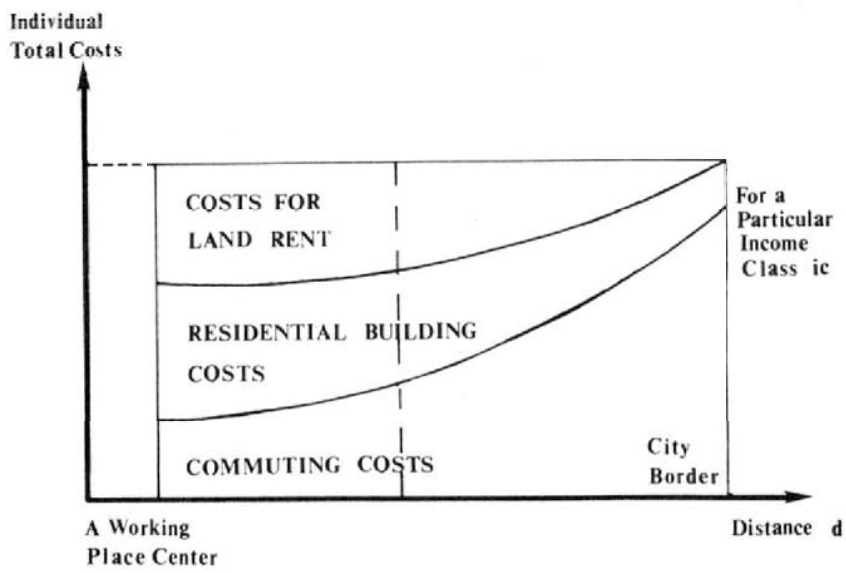

FIG. 2. Illustration of the extended model.

Using (13) it is possible to locate the node $n_{0}$, where $\mathrm{Ir}_{n 0}$ is minimum. If this minimum value of land rent is known, then the constant ic* can be determined with (10) for node $n_{0}$.

Once the value of ic* is known, the land rent at any node $n$ can be found using (11), that is, by the following expression (see Fig. 2):

$$
\operatorname{lr}_{n}=\frac{\alpha_{\ln }}{\alpha_{n}}\left(\mathrm{ic}^{*}-2 \cdot c_{\mathrm{bn}} \cdot \frac{\mathrm{NDAY}}{365}\right)-\alpha_{\ln } \cdot \mathrm{bc}_{n} .
$$

This equation corresponds to (5) in Mohring's model.

If the minimum value of land rent applies to a node located at the city limits, the minimum value of land rent can be assumed to equal the value of the land for agricultural use. In this model this minimum value of land rent was set to nought for the sake of simplicity. On the other hand, if the minimum value of land rent applies to a node inside the city, then one of the adjacent nodes is occupied by households of a different income class. The value of the land rent is then assumed to be the same for both nodes. (See Fig. 3.) This way of computing the land rents for each income class independently may lead to discontinuities in the sense that two city nodes near each other belonging to different income classes may have land rent values that differ significantly from each other. The fact that there are environmental differences between two adjacent nodes, perhaps separated by a road, could explain a situation with discontinuities. In addition, the number and sizes of the residential blocks (nodes) are given in the application of the extended model to Västerås. Thus, in this application, space is 


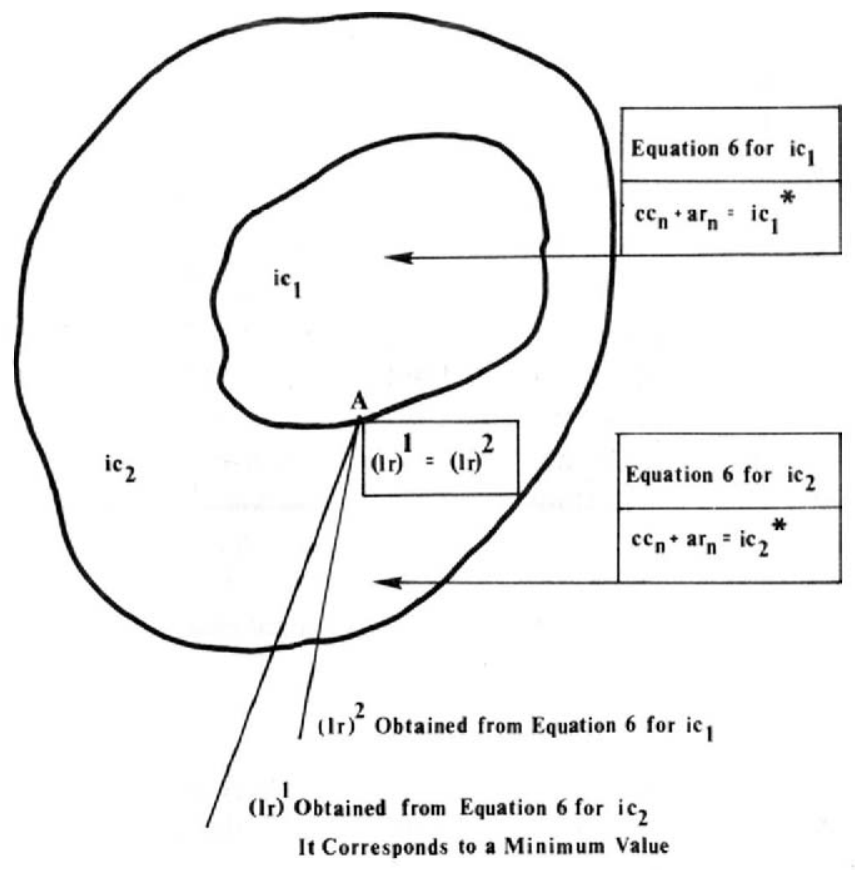

FIG. 3. Determination of the land rent distribution.

discrete, not continuous as in Mohring's model, which also can lead to discontinuities.

In fact, (6) considers only apartment rents and commuting costs explicitly. Environmental benefits (as well as other city activities) are also important factors in explaining differences in land rents in adjacent city nodes. Persons in the higher income classes demand more habitable area, greater environmental benefits, and more from facilities for other city activities. Then, roughly, it can be said that the differences in land rent values in two adjacent nodes may reflect a difference in the environmental benefits.

\section{APPLICATION OF THE EXTENDED MOHRING MODEL}

In general, the population of a particular node in a city depends on the populations of the other nodes. This strong interdependence among the nodal populations has to be assured by some simulation mechanism to find an equilibrium allocation of the population over the total city area. The rule used in the application discussed here is that the population density $D_{n}$ is 
made an exponential function of the land rent:

$$
D_{n}=A \exp \left(b \cdot \operatorname{lr}_{n}\right)
$$

where $A$ and $b$ are two parameters.

The density distribution for the initial time is given by the input data. The corresponding distribution of land rents is determined using the extended Mohring model just described. The density distribution is then determined for the various times of the simulation up to the time horizon by an iterative procedure. First the distribution of land rents found for the initial point of time is used. The parameter $b$ is set to an exogenously given value. The parameter $A$, and thus $D$, are determined by the condition that the entire population has to be contained within the city limits. A new land rent distribution is then computed. The procedure just described is then repeated.

It would also be possible to permit the functional form of the density distribution to be determined in the procedure (dynamic programming), rather than assuming an exponential function. But the simple exponential form perhaps suffices to capture some of the fundamental characteristics of population distributions in cities.

Equation (15) is an extension of the empirical function given by Colin Clark [8]. He assumed the population density to be simply a function of the radius to the city center. $R$. Muth [16, p. 91] suggested instead that the population density should be expressed as a function of the individual commuting costs. This was done in Andersson [3] and Andersson and Samartin [4]. The last step has been to express it as a function of land rent [5] as in Mills [14, p. 84]. In later analysis of urban density patterns the appropriateness of the exponential functional form has been put into serious doubt $[12,2]$. However, here this function is used explicitly to consider each working place center in the city separately. Also, the durability of city structures is explicitly dealt with in this model [19, 20]. The exponential function will not hold for many of the nodes due to the fact that the city has been built up during a long time. For instance, there may be nodes in the inner city with single-family houses that it is efficient to keep for several years, even though the actual land rent indicates that these nodes should have high-rise buildings. Furthermore, the exponential formula may not hold in every node to be built at a given time owing to possible restrictions on the total number of stories by the city planners.

The extended Mohring model presented above has been applied in an economic evaluation of city master plans for Västerås, Sweden. Details of the model used here are presented in Andersson and Samartin [5] and in [6]. Only a brief outline of the evaluation problem and model can be presented here. 
The various decisions that make up a city master plan cannot be determined independently of each other. For example, the minimum cost solution for a plan in which most of the housing is in the form of concentrated multifamily units calls for district heating and transportation by public means. At the opposite extreme, a plan calling for single-family houses in sprawling residential areas would likely require electrical heating and commuting by car. Therefore, one set of interdependent solutions to a consistent master city plan should be compared with another set of solutions to another plan.

Durability and irreversibility are two of the primary characteristics of an existing city. The pattern of buildings is a reflection of past expectations of future developments. These expectations may have changed drastically a number of times in the past. The buildings at different locations are of different vintages. Some buildings are likely very old and can be demolished and replaced by new buildings, while others have been built recently and may be used as they stand for a number of years [20]. Thus, a built-up city is not a world made of "putty," but of "clay" [19, pp. 31, 42-46]. Most of the existing residences will remain unchanged for several years.

There are in principle an infinite number of alternatives that could be used to adapt a city to a growing population. For practical purposes some combination of the following options might be considered:

1. to build residences on virgin land outside the built-up areas of the city;

2. to demolish old houses and replace them with new high-rise residential buildings;

3. to repair old houses;

4. to build new high-rise residential buildings on land not yet used or inside the built-up area.

The optimal adaptation process in a city with durable, irreversible features that is expecting future growth in its population will not be a smooth, continuous rebuilding throughout the entire city area. Rather, the expansion will take place in a limited number of areas within or outside the existing city. This is another reason why distinct alternative city master plans, adjusted to these realistic characteristics, may be necessary.

Three main parts of the model for the evaluation of master city plans can be distinguished: data, method, and results. The first part consists of the exogenously given variables and parameters. The second comprises all of the computational procedures used to obtain the results. These computations in turn can be divided into two steps. In the first step all of the relevant consequences of a given master city plan for the different city activities included in the model are simulated. Then the simulated consequences are 
evaluated economically, i.e., the total costs are computed. The results, i.e., the endogenous variables of interest for the city planners are obtained from the data and computations just described.

The algorithm used for the allocation of inhabitants is (15) presented above. In the economic evaluation of different alternatives, land costs are included as a part of the total costs. When calculating land costs, the following principles have been followed.

The costs for land in urban use vary depending on the location of the land within the city. To simplify the analysis of the treatment of land costs in various city locations, only two options are considered:

1. to build on virgin land outside the built-up area or

2. to build on land inside the built-up area that has not yet been used for building.

Thus, the question is how should the costs of land be treated in these two cases. In the first case, the best alternative use of the land would, it is assumed, be in agriculture. Thus the costs of land are determined by its value in such use. In the second case, we reason that land near the CBD is more of a scarce resource than land near the city limits. The reason for this is that it would be cheaper to live near the CBD (lower commuting costs, etc.) if land rents were the same at both locations. Also, there is less land near the CBD than there is near the city limits. Since the demand for land near the $\mathrm{CBD}$ is greater than for land near the city limits, the prices for land near the CBD would be bid up until an equilibrium distribution of land rents were obtained throughout the city according to the fundamental principle of the Mohring model. So, the greater land rents inside the built-up area reflect the higher opportunity costs there. Thus, in an equilibrium situation such land rents should be included in a calculation of the total costs of an alternative along with the other cost items, such as residential building and maintenance costs, building and maintenance costs for roads, commuting costs, heating costs, costs for schools, and so on.

A special problem of dynamic character is that the land rent distribution "shifts outward" continuously over time in a city that is expanding. In determining the number of stories and the size of the apartments at various locations, a value of land rent that is weighted over time should in principle be used owing to the phenomenon of durability and reversibility that is characteristic of the buildings.

Land costs per unit of time have been calculated using the following formula:

$$
\frac{\alpha_{n} \cdot p_{n}}{\alpha_{\ln }} \cdot \operatorname{lr} r_{n}
$$


Equation (16) is consistent with (8). Land costs calculated in this way are related to the land that is used for the residential buildings. This means that the costs for land used for other purposes are not explicitly considered. However, the costs of land for local roads, pavements, green areas, and the like included in the neighborhood area are lumped together with the land used for habitable space.

Two master city plans for Västerås, $B$ and $D$, have been evaluated using the concepts described above in [6]. Some of the results concerning land rent

$\begin{array}{lllllllll}\text { ALTERNATIVE B. INITIAL TIME (SEKM } & 2 \\ & \text { AND DAY) }\end{array}$
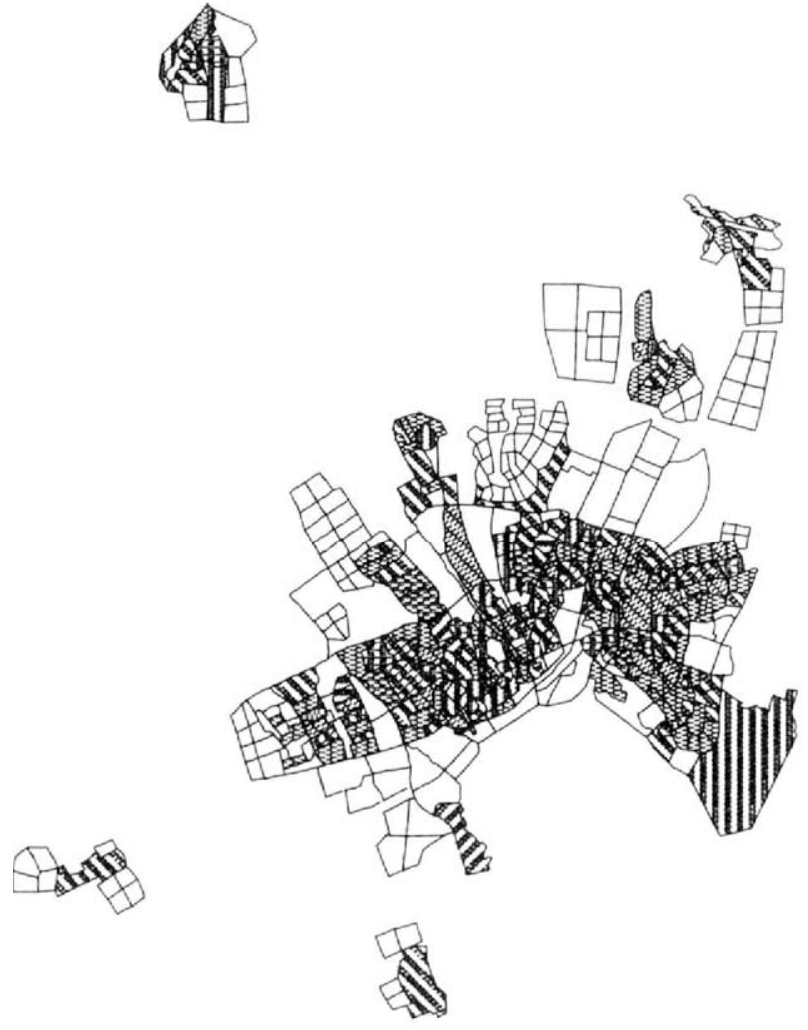

FIG. 4. Land rent distribution: Initial time. 


\section{ALTERNATIVE B。 PERIOD $1995 \ldots 2000$ (SEK/M ${ }^{2}$ AND DAY)}
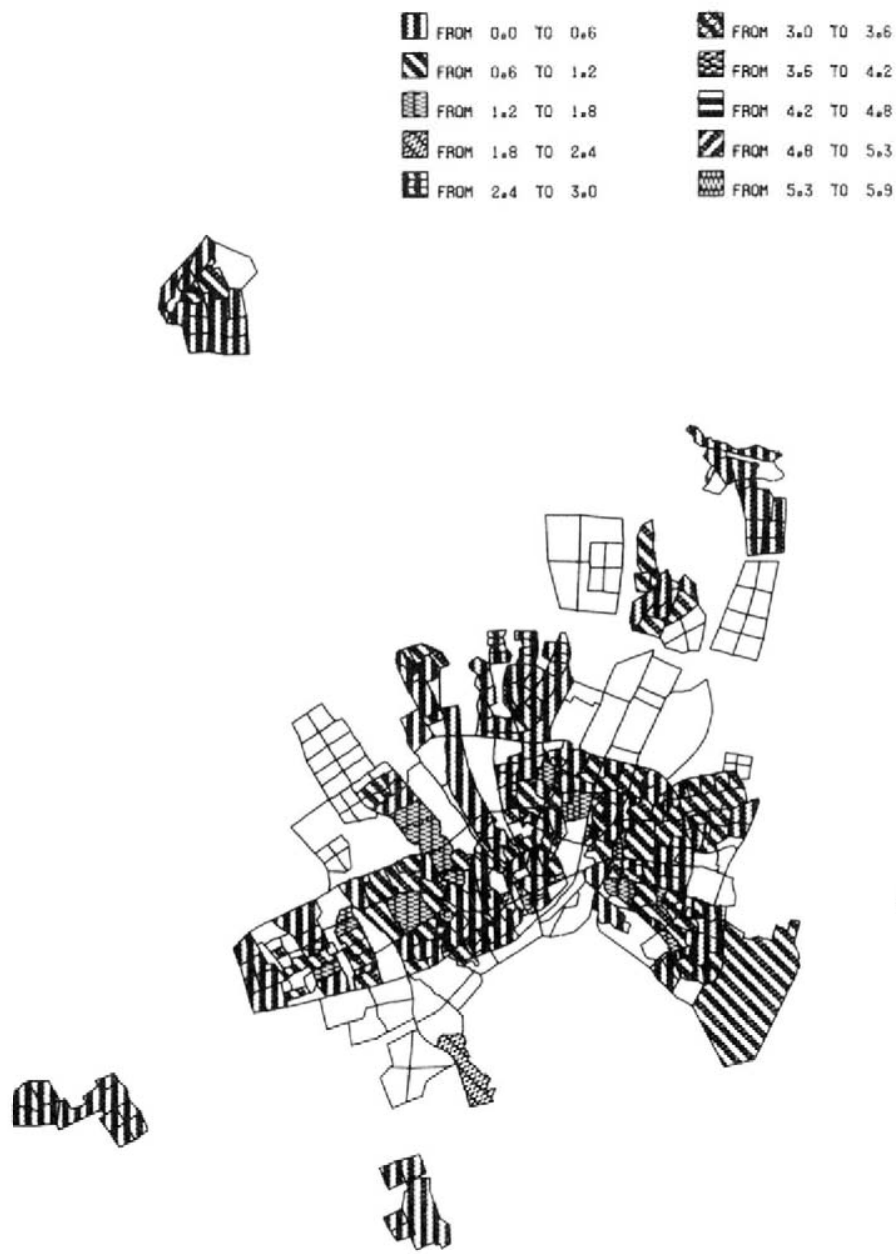

FIG. 5. Land rent distribution: Alternative $B$, period 1995-2000.

distribution or the initial time of the study, 1979, and for the final period of the plans, 1996-2000, for the two master city plans are illustrated in Figs. 4 through 6 in the form of maps produced by the computer. Plan $B$ is a "satellite" alternative; i.e., a great part of the new residences are located in "satellite" areas. Plan $D$ is a polar case in which the major part of the new residences are obtained through "urban renewal" in the inner city. The increase in land rents over time can be seen in the figures. 

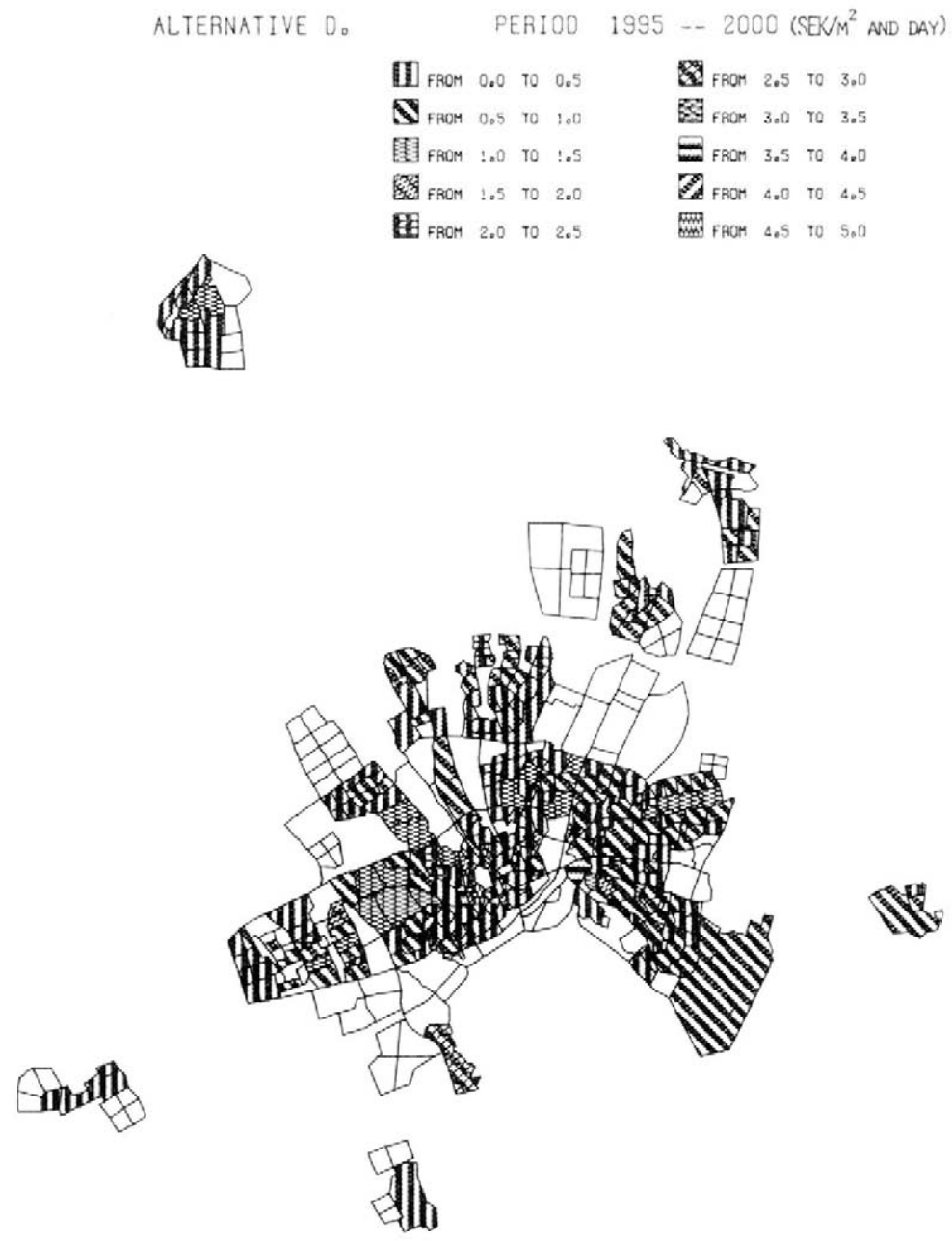

FIG. 6. Land rent distribution: Alternative D, period 1995-2000.

The land costs for the two alternatives calculated in present values as of 1979 are shown in Table 1. Land costs are somewhat greater in the urban renewal alternative.

\section{SUGGESTIONS FOR FURTHER RESEARCH AND CONCLUSIONS}

The extended Mohring model can be used to obtain several distributions for the values in real cities, such as land rent, population density, time 
TABLE 1

Land Costs for Alternatives $B$ and $D$ (SEK Millions)

\begin{tabular}{ccc}
\hline $\begin{array}{c}\text { Satellite } \\
\text { alternative }(B)\end{array}$ & $\begin{array}{c}\text { Urban renewal } \\
\text { alternative }(D)\end{array}$ & $\begin{array}{c}\text { Difference } \\
(D-B)\end{array}$ \\
\hline 17 & 40 & +23
\end{tabular}

values, price and income elasticities for habitable space, and so on. Some comments about these possibilities follow.

\section{a. Determination of Land Rent Distribution}

If apartment rents are known for the entire city area, then using (9) the land rent distribution can be found with

$$
\operatorname{lr}_{n}=\alpha_{\ln }\left(\mathrm{bc}_{n}-\frac{\mathrm{ar}_{n}}{\alpha_{n}}\right)
$$

For the purposes of (17) it is assumed that the average number of stories of residential buildings $\left(\alpha_{\ln }\right)$ at each city node is known. The supplied habitable space per individual $\left(\alpha_{n}\right)$ and the building costs $\left(\mathrm{bc}_{n}\right)$, which are functions of these two variables, are also given as data for each location in the city.

\section{b. The Introduction of Environmental Benefits}

Equation (7) could be expanded to consider the environmental benefits of ulfferent locations in an explicit manner:

$$
-\mathrm{eb}_{n}+\mathrm{cc}_{n}+\mathrm{ar}_{n}=\mathrm{ic}^{*}
$$

where

ic* is independent of the location in the city and constant for each income class and $\mathrm{eb}_{n}$ represents the environmental benefits at node $n$.

The problem is to find a quantitative value for the distribution of the environmental benefits over the city area. Mohring has dealt with this problem by introducing an empirical function that takes the particular environmental benefits owing to the proximity of a lake in Seattle, Washington, into consideration. 
c. Calculation of Price and Income Elasticities of the Demand for Habitable Space per Individual

If the following distributions over the city:

-apartment rents $\left(\mathrm{ar}_{n}\right)$,

-supplied habitable space per individual $\left(\alpha_{n}\right)$ and

-average disposable income per household $\left(\mathrm{ic}_{n}\right)$

are known and it can be assumed that demand and supply are in equilibrium, then the values of $\theta_{1}$ and $\theta_{2}$, the price and income elasticities for the demand for habitable space, can be calculated using (9) to determine $\alpha_{n}$ for each city node as follows:

$$
h\left(\mathrm{ic}_{n}\right)^{\theta_{1}} \cdot\left(\mathrm{ar}_{n}\right)^{\theta_{2}} \text {. }
$$

The values of $\theta_{1}$ and $\theta_{2}$ are estimated by the least-squares method.

\section{d. Determination of Apartment Rents}

Up to now it has been assumed that the initial land rent distribution would be obtained through a survey of statistical data. However, the values found in this way are usually distorted for several reasons. Mathematically, it is possible to determine apartment rents using (8) but where the values $x_{n}=\log \mathrm{ar}_{n}$ are not known in advance. A more complex regression problem must be solved to obtain the theoretical distribution of apartment rents.

\section{e. Time Values}

Finally, it is possible to apply the extended model presented here in a fashion similar to that used by Mohring to reveal the time values for commuting trips. However, this method of determining time values from the land rent distribution has several shortcomings and the risk of obtaining results that are inaccurate is considerable. More reliable results can be obtained by other methods; see Bruzelius [7], for example.

Mohring's model has proven useful in explaining several city activities using the concept of land rent, though it is based on some drastically simplified hypotheses. The model presented here is the fruit of an attempt to relax some of Mohring's simplifying assumptions. The extended model has already been applied in a method for the economic evaluation of city master plans in a real city. The main purpose of applying the extended Mohring model was to satisfy the requirements for the simulation of an equilibrium allocation of the population of the city over the city area. The land rent concept has also been used to calculate the land costs for alternative city 
master plans as a part of the total costs. Several additional applications of this model to real cities can be envisioned.

\section{APPENDIX A}

Residential Building Costs: $p_{\mathrm{o}}\left(\alpha_{1}\right)$

$$
p_{\mathrm{o}}\left(\alpha_{1}\right)=p_{\mathrm{o} 0}+p_{\mathrm{o} 1}+p_{\mathrm{o} 2}
$$

where

$p_{\mathrm{o} 0}$ are the residential construction costs;

$p_{\mathrm{ol}}$ are the foundation costs;

$p_{\mathrm{o} 2}$ are the maintenance costs.

The expressions for the above items are

$$
p_{\mathrm{o} 0}=p_{\mathrm{o} 0}\left(\alpha_{1}\right)=a_{\mathrm{o}} \alpha_{1}^{2}+b_{\mathrm{o}} \alpha_{1}+c_{\mathrm{o}}
$$

where $\alpha_{1}$ is the number of stories and $a_{\mathrm{o}}, b_{\mathrm{o}}, c_{\mathrm{o}}$ are constant coefficients.

$$
p_{\mathrm{ol}}=p_{\mathrm{o} 1 \text { mean }} \times l_{i}
$$

where $p_{\text {olmean }}$ is the foundation cost per meter of average ground area; $l_{i}$ is a land index reflecting the increase in the cost of foundations due to difference in soil conditions.

$$
p_{\mathrm{o} 2}=\left(p_{\mathrm{o} 0}+p_{\mathrm{o} 1}\right) Z_{0}
$$

where $Z_{0}$ is a coefficient that expresses the annual maintenance costs as a percentage of the total construction costs.

\section{REFERENCES}

1. W. Alonso, "Location and Land Use," Harvard Univ. Press, Cambridge, Mass. (1964).

2. J. E. Anderson, Cubic-spline urban-density functions, J. Urban Econ., 2, 155-167 (1982).

3. R. Andersson, "A Study of the Interdependence between Housing and Transportation in Cities," Swedish Council for Building Research, Stockholm, Document D11: 1976.

4. R. Andersson and A. Samartin, "Interdependence Among Housing, Heating and Transportation in Cities," Swedish Council for Building Research, Stockholm, Document D9: 1979.

5. R. Andersson and A. Samartin, A model for the economic evaluation of master city plans: A pilot study of Västerås, Appl. Math. Model., 7, Oct. (1983).

6. R. Andersson, A. Samartin, and J. Martinez, "The Economic Evaluation of Master City Plans. The Case of Västerås, Sweden,” Vols. I and II, Swedish Council for Building Research, Stockholm, D18: 1983 and D19: 1983. 
7. N. Bruzelius, "The Value of Travel Time. Theory and Measurements," Nationalekonomiska Institutionen, University of Stockholm (1978).

8. C. Clark, Urban population densities, J. Stat. Soc. Ser. A, 114 (1951).

9. D. Harrison and J. Kain, Cumulative urban growth and urban density functions, J. Urban Econ., 1, 61-98 (1974).

10. Y. Kanemoto, “Theories of Urban Externalities," North Holland, Amsterdam (1980).

11. L. Legey, M. Ripper, and P. Varaiya, Effects of congestion on the shape of a city, J. Econ. Theory, 6(2), 162-179 (1973).

12. J. McDonald and H. W. Bowman, Some tests of alternative urban population density functions, J. Urban Econ., 3, 242-252 (1976).

13. E. Mills, The value of urban land, in "The Quality of the Urban Environment," Resources for the Future, Johns Hopkins Press, Baltimore, Md. (1969).

14. S. Mills, “Urban Economics," Scott, Foresman, Glenview, Ill. (1972).

15. H. Mohring, Land values and measurement of highway benefits, J. Pol. Econ., 49 (1961).

16. R. F. Muth, "Cities and Housing," Univ. Chicago Press, Chicago (1969).

17. B von Rabenau, "Urban Dynamic Models. Maintenance and Replacement of Buildings, Spatial Development, and Economic Growth,” Ph.D. dissertation, University of California, Berkeley (1973).

18. R. Solow, Congestion costs and the use of land for streets, Bell J. Econ. Manage. Sci., 4, 602-618 (1973).

19. A. A. Walters, "The Economics of Road User Charges," IBRD, Baltimore, Md. (1968).

20. W. C. Wheaton, Development with durable but replaceable capital, J. Urban Econ., 12, 53-67 (1982). 